\title{
CORRESPONDENCE
}

\section{Fishery reform: many stocks secure}

We contest the widely held view that all European fish stocks and fisheries are in a dire state (see, for example, Nature 475, 7; 2011).

With the exception of cod, which remains heavily overfished, key stocks such as haddock, whiting, plaice and sole are all exploited close to the maximum sustainable yield.

We examined data for the 40 fish stocks assessed by the International Council for the Exploration of the Sea (ICES) that have reference points for maximum sustainable yields. These account for more than $90 \%$ of total allowable catches by European Union (EU) fishing fleets in the ICES areas.

The average fishing mortality for these stocks has declined in the past 10 years and their average spawning stock biomass has increased. In 2010, 17 of them $(43 \%)$ were fished at or below the level that delivers maximum sustainable yields a substantial improvement on $12.5 \%$ in 2000 . Fishing mortality has fallen since 2000 from 2.1 times the maximum sustainable yield to 1.3 times in 2010 .

Much remains to be done, but there are clear indications that actions implemented under the EU's Common Fisheries Policy (CFP) have been effective in bringing some stocks towards the target that will allow maximum sustainable yields. The CFP is under reform not because it has failed to achieve its targets, but because European Common Policies are reviewed every ten years (the last was in 2002).

After several decades of overexploitation, achieving this objective for all stocks will take time, but it is well under way. For some seas - the Mediterranean, for example where the situation for most fish stocks is critical, we do not
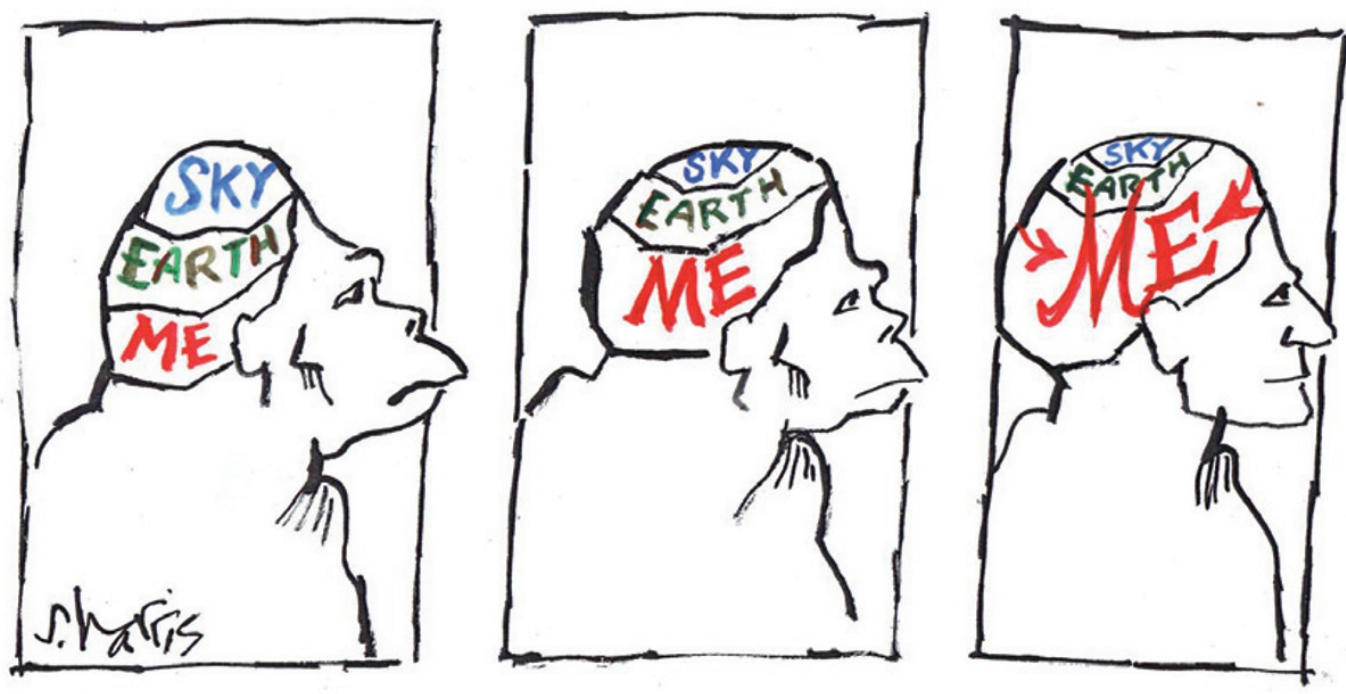

yet know whether management measures are delivering their intended objectives.

Massimiliano Cardinale on behalf of 9 co-signatories ${ }^{*}$, Swedish University of Agricultural Sciences, Lysekil, Sweden. massimiliano.cardinale@slu.se *See http://dx.doi.org/10.1038/ $476282 a$ for a full list of signatories.

\section{New name needed for unwise Homo?}

Homo sapiens was the name Carl Linnaeus assigned to our species in 1758 , when humanity may indeed have seemed 'wise' relative to others. Today, this name is up for debate, given our questionable ability to control the potential disasters we have unleashed.

An animal that imperils its own future and that of most other life forms and ecosystems does not merit a single 'sapiens', let alone the two we now bear.

We should be formally renamed to more accurately describe a species that is: exterminating thousands of others; releasing carbon, nitrogen and phosphorus in amounts exceeding Earth's natural cycles; devoting 50 times more resources to making weapons than to sustaining the food supply; destroying forests; degrading soil; polluting water; pillaging the oceans; and damaging the atmosphere on a planetary scale.

Changing our species' name might risk infringing some of the hallowed rules of nomenclature, but it would send an important signal about our present collective behaviour. Our present name Homo sapiens sapiens could then be reserved for a future type of human that is able to meet defined criteria such as, for example, living within the planet's boundaries (Nature 461, 472-475; 2009).

Julian Cribb Nicholls, Australian Capital Territory, Australia. jcribb@work.netspeed.com.au

\section{Rising ivory prices threaten elephants}

Kenya’s premier Samburu elephant population is the focus of a distressing surge in ivory poaching, coincident with an increase in illegal trading of ivory. This ivory is mainly destined for China (see go.nature.com/ czac $3 x)$. Effective protection of elephants depends partly on more conservation investment, but mainly on stemming the demand for ivory and eliminating blackmarket trade - actions that mandate leadership from and cooperation with China.

The Samburu elephants are one of the world's beststudied populations. Intensive monitoring has revealed that more have been poached in the past 2.5 years than in the previous 11 years. The highest poaching rates ever were recorded in the first 5 months of this year.

Poaching of males has resulted in a population with more than double the number of females to males. Poachers are now also targeting adult females, resulting in the loss of one or more in most families and leaving roughly one in five groups with no mature females. The number of orphans in the population is increasing rapidly.

These changes correlate with a near tripling of the total number of seizures of illegal ivory in or coming from Kenya (see go.nature.com/k9bkwy) and with rising ivory prices. Local black-market ivory prices around Samburu have more than doubled since 2007, and are an order of magnitude greater than in 1990. At current local prices, the ivory of the largest male elephant poached in the Samburu population is equivalent to 1.5 years' salary for a wildlife ranger or 15 years' 